\title{
The Misalignment between Hospital Planning Frameworks and their Planning Environment - A Conceptual Matching Approach
}

\author{
Vivi Thuy Nguyen ${ }^{1}$, Anita Friis Sommer ${ }^{2}$, \\ Kenn Steger-Jensen ${ }^{1}$, and Hans-Henrik Hvolby ${ }^{1}$ \\ ${ }^{1}$ Department of Mechanical and Manufacturing Engineering, Aalborg University, Denmark \\ (vivi, kenn, hhh) @m-tech. aau.dk \\ ${ }^{2}$ Department of Engineering, University of Cambridge, UK \\ afs35@cam.ac.uk
}

\begin{abstract}
Scientifically developed hospital planning frameworks have emerged during the last decade to support and prescribe planning and control practice in hospitals. The three presented frameworks are generally based on manufacturing planning and control frameworks attuned for manufacturing environments. This is critical to the adaptability of the frameworks, since manufacturing environments are focused on optimization of repetitive production processes whereas hospital processes are characterised by complex problem-solving processes with a high degree of uncertainty. In this paper, we identify and describe the misalignment from an environment variables perspective through analysis and comparison of three prominent hospital planning frameworks and hospital planning variables derived from empirical studies in existing research.
\end{abstract}

Keywords: Hospital planning frameworks, hospital planning and control, planning and control frameworks, hospital environment, conceptual matching.

\section{Introduction}

Inspired from manufacturing industry, scholars from the field of operations management have proposed several frameworks for effective and efficient hospital planning. However, the planning environment of a hospital is different from the planning environment of a manufacturing company, and since research on hospital planning and control is a relatively new research area, little empirical evidence currently supports the applicability of planning and control frameworks in a hospital environment. Thus, the purpose of this paper is to conduct evaluations of adapted frameworks for hospital planning and control in relation to the planning environment of hospitals.

Hence, the main focus of this paper is the relation between the planning environment and the planning framework used for hospital planning in practice. Jonsson and Mattson [1] used a similar analysis between planning environment and planning methods in manufacturing environments both empirically and conceptually. However, this paper will only focus on the conceptual matching between planning frameworks and planning environment, where the reasoning is that the planning environment and

B. Grabot et al. (Eds.): APMS 2014, Part II, IFIP AICT 439, pp. 675-682 2014.

(C) IFIP International Federation for Information Processing 2014 
planning framework must be aligned and match in order to derive value from the planning methods in practice. Based on this notion, the three dominant planning frameworks for hospitals are first presented followed by identification of hospital environment variables through existing research. Afterwards, the appropriateness of the planning frameworks in the hospital environment is conceptually explained.

\section{Conceptual Frameworks for Hospital Planning and Control}

During the last decade several hospital planning and control frameworks have been proposed, many of which are based on or heavily inspired by frameworks from production planning and control scholar, like Hax and Meal [2], Silver et al [3], and Vollman [4]. Through a broad literature review, three predominant frameworks have been found to highlight the variety between existing frameworks, and are also the most academically recognized; Roth \& Van Dierdonck [5], Vissers et al.[6], and Hans et al. [7]. These frameworks have inspired researchers within the field to structure the scope of research studies such as literature reviews [5], adaption to different areas of health care [6] [7], and further development of the frameworks [8]. An overview of the characteristics of the three frameworks is presented in Table 1.

Table 1. Characteristics of three dominant hospital planning frameworks

\begin{tabular}{lllll}
\hline Author & Objective & Focus & $\begin{array}{l}\text { Hierarchical } \\
\text { Planning levels }\end{array}$ & Environment Assumptions \\
\hline $\begin{array}{l}\text { Roth and } \\
\text { Dier- } \\
\text { donck, }\end{array}$ & $\begin{array}{l}\text { Mini- } \\
\text { mizing } \\
\text { cost }\end{array}$ & Patient flows & $\begin{array}{l}\text { 3 levels (Aggregate } \\
\text { admission planning, master } \\
\text { admission planning, } \\
\text { hospital resource planning, } \\
\text { order releasing planning) }\end{array}$ & $\begin{array}{l}\text { Predefined patient pattern, } \\
\text { managing capacity an } \\
\text { resources, procedure and } \\
\text { treatment protocol } \\
\text { standardized }\end{array}$ \\
\hline $\begin{array}{lllll}\text { Visser et } \\
\text { al, 2001 }\end{array}$ & $\begin{array}{llll}\text { Optimize } \\
\text { resource } \\
\text { utilization }\end{array}$ & $\begin{array}{l}\text { One } \\
\text { department }\end{array}$ & $\begin{array}{l}\text { 5 levels (strategic, patient } \\
\text { volumes, resources, patient } \\
\text { groups, patient) }\end{array}$ & $\begin{array}{l}\text { Predictive, homogenous } \\
\text { patient group, predictable } \\
\text { treatment process, low } \\
\text { variability on patient's } \\
\text { condition }\end{array}$ \\
\hline $\begin{array}{l}\text { Hans et } \\
\text { al, 2011 }\end{array}$ & $\begin{array}{l}\text { Efficient } \\
\text { hospital } \\
\text { decision } \\
\text { making }\end{array}$ & $\begin{array}{l}\text { Entire } \\
\text { healthcare } \\
\text { organization }\end{array}$ & $\begin{array}{l}\text { 4 levels (strategic, tactical, } \\
\text { offline operational, online } \\
\text { operational) }\end{array}$ & $\begin{array}{l}\text { Elective and urgent patients } \\
\text { only, integration of all } \\
\text { managerial areas in health } \\
\text { care delivery, operational } \\
\text { integration focus }\end{array}$ \\
\hline
\end{tabular}

In 1995, Roth \& Dierdonck introduced a framework called "Hospital Resource Planning" aimed specifically at healthcare cost reduction through improved hospital planning and control. The framework is based on the introduction of a classification system that identifies the health care services received by patients. The framework is directly inspired by the manufacturing system approach, with materials requirement 
planning as the backbone. The framework considers both the resource capacity planning and material planning of hospitals and introduces a classification system as the bill of resources to classify products or services hospitals provides including calculating prices of services [9]. The study is an exploratory study based on longitudinal data from two hospitals, one 300-bed community hospital and one 1,100-bed teaching hospital. Hence, they acknowledge that the traditional MRP logic has shortcomings. Thus, the key assumptions of the framework are that:

1. Hospitals have superior capabilities for managing capacity and resources.

2. Procedure and treatment protocols are standardized, and variation in patient flow decreases over time.

3. All necessary processes are well defined.

Based on the requirements, the framework will fit a hospital environment with repetitive processes and variables similar to a mass-production environment with mature planning and control processes.

The second framework was developed by Vissers et al. in 2001 [10]. The framework is based on existing literature at the time, partly inspired by De Vries et al.[11], which was limited to resources capacity planning and patient flow, including optimization of batching rules for resource utilization, frequency of service to a patient group and size, and composition patient batches. However, most of the literature within hospital planning and control takes point of departure of this paper in relation to their empirical studies such as within operating theatre [12] [13] [14]. The framework prescribes identification of planning horizons and different types of decisions that have to be taken in an organization, distinguished by five hierarchical levels including strategic planning, patient volumes planning, resource planning, single patient/patient groups planning. The key assumptions of the framework are that:

1. Hospitals are organized in independent business units.

2. The patient-group is homogeneous

3. One primary predictable and stable process flow of treatment for each patient group.

Thus, this framework is suitable for a predictable process after the treatment plan setup, including low variety in the treatment process, common requirements in quality and service, homogeneous in resource requirement and no requirements for flexibility within the patient-group.

Finally, Hans et al. [15] proposed a generic health care framework with the objective to structure the various planning and control functions in a health care system, which is the latest framework among these three The framework is based on hierarchical planning principles divided by planning horizons and is intended to be applicable to any type of health care delivery. Furthermore, Hans et al. [15] argue that traditional planning frameworks are often too simplistic as they are oriented towards one managerial area (in particular resource capacity planning or material planning) and neglect the reactive decision functions, which are important given the inherently stochastic nature of health care processes. The framework integrates the managerial areas of medical planning, resource capacity planning, materials planning, and financial planning. These are 
integrated due to the authors' assumption that collaboration and dialogue between all types of managers in healthcare planning is a core mechanism for optimized planning of the entire system. Related to the broad scope of the framework, the prerequisites of the framework are blurred. The framework can be applied at all health care levels from a supply chain of care providers down hospital departments, and thus from a contingent viewpoint, the framework must be tailored according to environment characteristics. Hence, the key assumptions of the framework are that:

1. Planning is an interdependent process between managerial hospital areas.

2. Patient groups are homogeneous across the healthcare system.

3. Two distinctive processes; reactive processes (offline (elective) patient), proactive processes (online (emergency) patient)

\section{Hospital Environmental Variables}

Jonsson and Mattsson [1] identify that environmental variables have significant impact on the sustainability of planning methods in manufacturing companies. Therefore, the hospital environmental variables must be identified. All three framework studied are addressing the environmental characteristic, which can be divided into three groups of patient, resource, and hospital process.

In health care, the patient is both a customer and involved in the health care production process [16]. Demand can be defined as the patients' need for health care services, which is partly predictable and partly random too which it is similar to the demand in the industry [17]. However, the differences between a traditional definition of a product and the patient as a product are that the patient's condition may even change during the time while waiting as well as during the process of treatment [12], which is causing the high variability and uncertainty in hospital planning and control. Patients are classified in the range of medical urgency categorization at hospitals, which is based severity of their condition in order to prioritize job task of patients; elective, semi-urgent, and emergency [18]. Looking from the planning point of view, it is frequently interrupted by both the unexpected arrival of critically emergency patients and by the changes of the patients' condition during the admission process [16]. In order to capture patients' needs for health care, it requires a flexibility and agility in operations from the hospital. There is a high variability of patients in hospitals, needing individual hospital health care services, and to some extent they can be grouped based on their medical profile [11]. However, patients also need an individual evaluation of the medical profile complexity in order to determine the process of treatment generating variation within a patient group [10]. Furthermore, patient volume needs to be considered especially in relation to limited resources [11] Hence, the patient variables are deduced to be patient medical profile complexity, medical urgency, patient variety, demand uncertainty, and patient volume.

The resources in a hospital environment refer to all resources involved in the hospital's planning and control processes. The main resource types include human resources (doctors, nurses, secretaries, porters, and planning personnel), medical equipment (operation packages and medicines ), and facilities (beds and operating theatres) [19],[20]. Furthermore, the resource type is dependent on the profiles and 
experience of the particular resource. For human resources the profile includes, for instance, the nurse profile (operational or ward), and the doctors' clinical profile including their experience. For medical equipment the profile relates to the treatment area, and the experience is for instance the maturity of the medicine technology or treatment, which in some situations is short-lived down to a few hours lifetime from development. Apart from the main resource types, supporting resources are also essential to include as an environmental variable [21]. Supporting resources include all influencing resources that are not directly part of the hospital process in question including for instance hospital managers and expensive critical care resources. Thus, the hospital resource variables include; resource types, profile, experience, and supporting resources.

The hospital processes can be divided into operation processes and organizational support processes, and operational processes can be further divided into diagnostics process phase and therapy process phase [11]. The operation processes are driven by resources such as medical specialists, mainly in charge of the medical treatment, researching and teaching with the aim of providing and developing new medical methods of health care services to increase the inhabitants' health quality of life [22] [10]. The individual caregivers such as doctors and nurses are patient-centred in their work, where different knowledge and experience has an impact in planning and scheduling incoming patients on top of the degree of complexity of the process itself [23]. The organizational processes are often divided in groups of clinical specialties focusing on single procedures or patient groups in order provide most effective care for the patients. Building up around disciplines enhances the specialization of treatments of different patient group, where the clinical staff develops an in- depth knowledge and experience, resulting in a high quality, fully integrated, operational organization at its disposal [12]. Thus, the hospital processes are identified as the diagnostic and therapy processes, process task complexity, interdependency with other resources, and organization support processes. In Table 2, the hospital planning environment variables are presented within the category of patient, resources, and hospital processes based the study of this section.

Table 2. Overview of hospital planning environment variables

\begin{tabular}{lll}
\hline & \multicolumn{2}{c}{ Hospital environmental variables } \\
\hline Patient & Resources & Hospital processes \\
\hline Patient medical profile & Resource types & Diagnostics and therapy phases \\
\hline Medical urgency & Profile & Process task complexity \\
\hline Patient variety & Experience & $\begin{array}{l}\text { Interdependency with other } \\
\text { resources }\end{array}$ \\
\hline Demand uncertainty & Supporting resources & Organizational support processes \\
\hline Patient volume & & \\
\hline
\end{tabular}




\section{$4 \quad$ Conceptual Matching}

Overall, frameworks presented above are addressing the hospital environmental variables to some extent, as they all include aspects of patient variables, resources, and the hospital processes. However, the frameworks generally simplify the complexity of the system by only including the simplest variables, omitting, for instance, the condition of the patient, their medical profile, or the variety of patients [8]. In the three frameworks prioritization of patients is only briefly addressed through the by 'first in first out' principles, whereas the medical urgency is not being addressed. Hans et al [15] acknowledge the importance of medical urgency in the planning processes by including both elective patient and emergency patient processes. Even so, uncertainty of the medical profile and the patient's condition is missing along with the need for flexibility in the health care system generating robustness of the framework. On the other hand, Visser et al [10] acknowledge the need for high flexibility during the diagnostic process due to high degree of uncertainty, but then choose to limit the framework to the therapy process phase, where the process flow is more predictable. Thus, it indicates that hospital planning can be improved through inclusion of patient variety and medical profile variables in applied hospital planning frameworks.

The theoretical frameworks generally regard resources as a constraint in hospital planning and consider mainly the resource type variable. However, as the environment variables imply, this approach is not sufficient in planning environments with varying resource profiles, varying experience, and the influence of supporting resources. One consequence is the lack of precision in hospital planning practice in situations where these variables are not distributed evenly according to the applied planning model. Hence, it indicates based on the findings that hospital planning accuracy can be improved by inclusion of resource profiles, experience, supporting resources in the hospital planning model oriented around patients.

The planning frameworks in this paper are all hierarchical in nature, where the purpose is to improve coherent and efficient planning of operational hospital processes. However, the point of departure such as objectives and point of view differ. In Visser et al [10], one of the assumptions is that hospitals are organized in independent business units, whereas, Hans et al [15] emphasize the need to incorporate both multiple managerial areas to capture the complex relationships in health care and the reactive decision functions, which are important given the inherently stochastic nature of health care processes. Oppositely, Roth and Van Dierdonck [24] focus at the process flow but disregard the hospital organization. In a sense, the hospital can be categorized as a hybrid organization as introduced by Van Merode et al [12], where one part of the organization is of a mechanistic nature suited for rather deterministic processes and another is a more organic part, directed to non-routine, innovative tasks. Thus, suggest for further research that hospital planning include both deterministic and complex process models in accordance with phases, process task complexity, interdependency and influencing support processes'.

The mismatch identified between the theoretical frameworks and theoretically derived environment variables generates incentives for further investigation of how a 
more general hospital environment relates to applied frameworks in practice. Thus, based on the developed propositions we suggest the following research question for an empirical explorative study: "What is the misalignment between hospital environmental variables and applied planning frameworks, and what are the effects on operational practice? "

\section{Conclusion}

This paper contributes to existing research with a conceptual analysis of existing hospital planning and control frameworks, and a set of propositions for further research improving the match between planning frameworks and the hospital environment. Based on the study, it indicates that hospital planning frameworks need a more integrated holistic planning perspective. It is found that the hospital environmental variables can be grouped into three; patient, resource, and process. However, existing frameworks do not properly addresses these variables in the hospital planning environment, nor do they acknowledge the hybrid nature of hospital organization.

We propose that the existing frameworks are misaligned with several environment variables, and thus further research on alignment is recommended. This includes explorative in-depth studies on the empirical matching between hospital environments and applied planning frameworks.

\section{References}

1. Jonsson, P., Mattsson, S.-A.: The implications of fit between planning environments and manufacturing planning and control methods. Int. J. Oper. Prod. Manag. 23, 872-900 (2003)

2. Hax, A.C., Meal, H.C.: Hierarchical integration of production planning and scheduling. DTIC Document (1973)

3. Silver, E.A., Pyke, D.F., Peterson, R.: Inventory management and production planning and scheduling. Wiley, New York (1998)

4. Vollmann, T.: Manufacturing Planning and Control Systems for Supply Chain Management: The Definitive Guide for Professionals. McGraw-Hill Education (2005)

5. Hulshof, P.J.H., Kortbeek, N., Boucherie, R.J., Hans, E.W., Bakker, P.J.M.: Taxonomic classification of planning decisions in health care: a structured review of the state of the art in OR/MS. Health Syst. 1, 129 (2012)

6. Adan, I.J.B.F., Vissers, J.M.H.: Patient mix optimisation in hospital admission planning: a case study. Int. J. Oper. Prod. Manag. 22, 445-461 (2002)

7. Testi, A., Tanfani, E., Torre, G.: A three-phase approach for operating theatre schedules. Health Care Manag. Sci. 10, 163-172 (2007)

8. Brailsford, S., Vissers, J.: OR in healthcare: A European perspective. Eur. J. Oper. Res. 212, 223-234 (2011)

9. Forgione, D.A., Vermeer, T.E., Surysekar, K., Wrieden, J.A., Plante, C.C.: DRGs, Costs and Quality of CARE: An Agency Theory Perspective. Financ. Account. Manag. 21, 291-308 (2005)

10. Vissers, J.M.H., Bertrand, J.W.M., De Vries, G.: A framework for production control in health care organizations. Prod. Plan. Control. 12, 591-604 (2001) 
11. De Vries, G., Bertrand, J.W.M., Vissers, J.M.H.: Design requirements for health care production control systems. Prod. Plan. Control. 10, 559-569 (1999)

12. Van Merode, G.G., Groothuis, S., Hasman, A.: Enterprise resource planning for hospitals. Int. J. Med. Inf. 73, 493-501 (2004)

13. Hans, E., Wullink, G., Van Houdenhoven, M., Kazemier, G.: Robust surgery loading. Eur. J. Oper. Res. 185, 1038-1050 (2008)

14. Guerriero, F., Guido, R.: Operational research in the management of the operating theatre: a survey. Health Care Manag. Sci. 14, 89-114 (2011)

15. Hans, E.W., Houdenhoven, M.V., Hulshof, P.J.: A framework for health care planning and control, vol. 168, pp. 303-320. Springer, N. Y. (2011)

16. Hall, R., Belson, D., Murali, P., Dessouky, M.: Modeling patient flows through the healthcare system. Patient Flow Reducing Delay Healthc. Deliv., 1-44 (2006)

17. Womack, J.P., Jones, D.T.: Lean thinking: banish waste and create wealth in your corporation. Simon and Schuster (2010)

18. Vos, L., Groothuis, S., van Merode, G.G.: Evaluating hospital design from an operations management perspective. Health Care Manag. Sci. 10, 357-364 (2007)

19. Blake, J.T., Carter, M.W.: A goal programming approach to strategic resource allocation in acute care hospitals. Eur. J. Oper. Res. 140, 541-561 (2002)

20. Harper, P.R.: A framework for operational modelling of hospital resources. Health Care Manag. Sci. 5, 165-173 (2002)

21. Carter, M.: Diagnosis: mismanagement of resources. MS TODAY 29, 26-33 (2002)

22. Kopach-Konrad, R., Lawley, M., Criswell, M., Hasan, I., Chakraborty, S., Pekny, J., Doebbeling, B.N.: Applying Systems Engineering Principles in Improving Health Care Delivery. J. Gen. Intern. Med. 22, 431-437 (2007)

23. Williams, S., Crouch, R.: Emergency department patient classification systems: A systematic review. Accid. Emerg. Nurs. 14, 160-170 (2006)

24. Roth, A.V., Van Dierdonck, R.: Hospital Resource Planning: Concepts, Feasibility, and Framework. Prod. Oper. Manag. 4, 2-29 (1995) 